Publised in Learning and Individual Differences

Cite this article as:

Brandmo, C., \& Bråten, I. (2018). Investigating relations between beliefs about justification for knowing, interest, and knowledge across two socio-scientific topics. Learning and Individual Differences, 62, 89-97.

Online: https://doi.org/10.1016/j.lindif.2018.01.010

\title{
Investigating Relations Between Beliefs About Justification for Knowing, Interest, and Knowledge Across Two Socio-Scientific Topics
}

\author{
Christian Brandmo and Ivar Bråten \\ University of Oslo, Norway
}

\begin{abstract}
Author Note
Address for correspondence: Christian Brandmo, Department of Teacher Education and

School Research, P.O. Box 1099 Blindern, NO-0317 Oslo, Norway.

E-mail: christian.brandmo@ils.uio.no
\end{abstract}

Acknowledgement: The research reported in this article was funded by grant 237981/H20

from the Research Council of Norway to Ivar Bråten.

Date accepted: January 19, 2018 


\begin{abstract}
In a sample of 281 Norwegian upper-secondary school students, structural equation modeling was used to test hypothesized relationships between beliefs about justification for knowing, interest, and knowledge across two controversial socio-scientific topics: climate change and nuclear power. Results indicated that beliefs in justification by multiple sources had a positive direct effect on knowledge about climate change and positive indirect effects on knowledge about both topics mediated by topic interest. Beliefs in personal justification had only a negative direct effect on knowledge about climate change, and beliefs in justification by authority were not related to knowledge about any of the topics, neither directly nor indirectly. Findings are considered in light of the existing literature on epistemic beliefs concerning justification for knowing and suggestions for future research are offered.
\end{abstract}

Keywords: Epistemic beliefs, justification for knowing, topic interest, topic knowledge, socioscientific topics. 


\section{Investigating Relations Between Beliefs About Justification for Knowing, Interest, and Knowledge Across Two Socio-Scientific Topics}

\section{Introduction}

In the 21 st century, gaining accurate knowledge about controversial socio-scientific topics is more important than ever. In democratic societies, such topics are often publicly debated (Bromme \& Goldman, 2014; Sinatra, Kienhues, \& Hofer, 2014), and participation in a constructive democratic discourse on how to approach and solve them requires that people have some common ground in terms of basic topic knowledge despite other disagreements they might have (Sinatra et al., 2014). In an educational context, it is therefore pertinent to investigate other psychological constructs that may underlie students' knowledge about socioscientific topics. In the current study, we focused on two such constructs, epistemic beliefs concerning the domain of science and topic interest, as predictors of students' knowledge about two publicly debated and essential socio-scientific topics: climate change and nuclear power plants. Additionally, we investigated the extent to which interest in these topic might mediate the effects of epistemic beliefs on students' knowledge about them.

\section{Theoretical Assumptions and Prior Research}

Within educational psychology, epistemic beliefs are considered forms of personal epistemology that concern lay persons' views about the nature of knowledge and the nature of knowing (Hofer \& Bendixen, 2012). Several dimensions of epistemic beliefs have been focused in the literature, including beliefs about the certainty, simplicity, and source of knowledge, as well as the justification for knowing (Hofer \& Pintrich, 1997; Schommer, 1990). However, in the last decade, particular attention has been given to beliefs about justification for knowing, which concern the ways in which individuals evaluate knowledge claims (Hofer \& Bendixen, 2012). A main impetus for this direction within epistemic belief 
research has been the philosophically inspired conceptualization proposed by Greene, Azevedo, and Torney-Purta (2008). The core argument of these authors was that thinking about justification for knowing is the centerpiece of personal epistemology, especially distinguishing between justification by an internal personal source and justification by an external authoritative source. Later, Greene, Torney-Purta, and Azevedo (2010) provided empirical evidence for the validity of these two dimensions concerning justification for knowing at a domain-specific level (i.e., in math and history).

In a think-aloud study framed by Greene et al.’s (2008) theoretical work, Ferguson, Bråten, and Strømsø (2012) also found that students justified knowledge claims by both personal opinion and an external authoritative source when reading about a controversial socio-scientific topic. In addition, however, participants were found to justify knowledge claims by multiple sources, meaning that they judged knowledge claims by checking several sources of information for consistency. In a later study using a questionnaire designed to capture all three dimensions (i.e., personal justification, justification by authority, and justification by multiple sources), Ferguson, Bråten, Strømsø, and Anmarkrud (2013) further validated this trichotomous framework concerning justification for knowing, which also forms the basis for the current empirical investigation. Within this framework, personal justification refers to the evaluation of knowledge claims in relation to one's own views or opinions about the claims in question, justification by authority refers to the evaluation of knowledge claims by appealing to a reputable external source (e.g., a teacher or a scientist), and justification by multiple sources refers to the evaluation of knowledge claims by cross-checking and corroborating across different information sources. Of note is that beliefs falling on these three epistemic belief dimensions are considered domain-specific in the sense that they vary across academic domains or disciplines (Muis, Bendixen, \& Haerle, 2006). ${ }^{1}$ 
A number of recent empirical studies have established links between beliefs about justification for knowing and learning and performance (Bråten \& Strømsø, 2010; Conley, Pintrich, Vekiri, \& Harrison, 2004; Greene et al., 2010; Mason, Ariasi, \& Boldrin, 2011; Mason, Boldrin, \& Ariasi, 2010; Muis, 2008; Muis \& Franco, 2010; Strømsø \& Bråten, 2009). With respect to research conducted within the trichotomous framework described above, the general trend is that beliefs in personal justification are negatively related to performance whereas beliefs in justification by multiple sources are positively related to performance (Bråten, Anmarkrud, Brandmo, \& Strømsø, 2014; Bråten \& Ferguson, 2014; Bråten, Ferguson, Anmarkrud, Strøms $\varnothing, \&$ Brandmo, 2014; Bråten, Ferguson, Strøms $\varnothing$, \& Anmarkrud, 2013; Bråten, Ferguson, Strømsø, \& Anmarkrud, 2014; Ferguson \& Bråten, 2013; Kendeou, Braasch, \& Bråten, 2016; Trevors, Kendeou, Bråten, \& Braasch, 2017). Of note is that different measures of performance have been used in this body of research, ranging from multiple text comprehension to conceptual change learning and science achievement. Additional evidence for a positive relationship between beliefs in justification by multiple sources and learning and performance comes from research on Internet-specific epistemic beliefs (i.e., beliefs about what knowledge and knowing are like on the Internet; Bråten, Strøms $\varnothing, \&$ Samuelstuen, 2005). In brief, this body of work indicates that higher beliefs in the need to check knowledge claims against other information sources positively predict adaptive strategy use and Internet-based learning (Chiu, Liang, \& Tsai, 2013; Lee, Chiu, Liang, \& Tsai, 2014; Kammerer, Amann, \& Gerjets, 2015; Kammerer, Bråten, Gerjets, \& Strømsø, 2013; Strømsø \& Bråten, 2010; see also, Greene, Yu, \& Copeland, 2014).

Findings concerning justification by authority have been less consistent, however. While justification by authority have been found to be unrelated to performance in some studies (Bråten et al., 2013; Bråten, Ferguson, Strøms $\varnothing$, et al., 2014; Kendeou et al., 2016), other research has found a positive relationship between this variable and performance in 
specific task contexts and cultural groups (Braasch, Bråten, Britt, Steffens, \& Strømsø, 2014; Strømsø, Bråten, Anmarkrud, \& Ferguson, 2016). Moreover, a recent study by Bråten and Ferguson (2014) suggested that a positive relationship between justification by authority and performance may be limited to justification by scientific authority.

In addition to research on epistemic beliefs in relation to learning and performance, a number of studies have examined relationships between epistemic beliefs and motivation constructs (for a recent review, see Chen \& Barger, 2016). This line of research is grounded in Hofer and Pintrich's (1997) landmark review of personal epistemology, in which they proposed that beliefs about knowledge and knowing may be activated by specific topics and domains and impact learners' motivation with respect to those topics and domains. Accordingly, epistemic beliefs can be considered to indirectly affect learning and performance through motivation (Hofer \& Pintrich, 1997; Pintrich, 2002). Further specification of this idea of mediation through motivation is found in theoretical work by Buehl (2003) and Muis (2007), who suggested that epistemic beliefs influence motivation constructs such as self-beliefs, values, and achievement goals. Such motivation constructs may in turn influence learners' knowledge generation and achievement (see also, Barger \& Linnenbrink-Garcia, 2017). On the basis of this view, we set out to test a model where a particular value-related motivation construct, individual topic interest, was assumed to mediate the effects of the different types of justification beliefs included in Ferguson et al.'s (2012, 2013) trichotomous framework on students' knowledge. Of note is that individual interest in a particular topic or activity is considered a part of the value component of motivation within expectancy-value theory of achievement motivation (Wigfield \& Eccles, 2000). In the present study, we targeted students' interest and knowledge with respect to two scientific topics (i.e., climate change and nuclear power). And, because our measures of 
interest and knowledge concerned scientific topics, justification for knowing beliefs were measured with respect to the domain of science.

Of note is that individual or personal interest, which refers to a relatively stable motivational disposition to be attracted by and engaged in specific topics or domains, figures prominently within motivation theory (Hidi \& Renninger, 2006; Schiefele, 1999, 2009; Schunk, Meece, \& Pintrich, 2014; Wigfield \& Eccles, 2000), as well as in theories of domain learning (Alexander, 1997; 2012). For example, Schiefele (1999) has regarded individual interest as a dispositional motivational characteristic defined by the positive feelings and personal significance attributed to particular topics or domains, and in Alexander's (1997) model of domain learning, individual interest involves an investment and involvement in a particular field that interacts with knowledge and strategic processing. Also, the will to engage in a topic is regarded as an aspect of individual topic interest by several theorists (e.g., Alexander, 1997; Hidi \& Renninger, 2006; Schunk et al., 2014). Much motivation research has documented that interest in particular topics and domains positively predicts performance with respect to those topics and domains, presumably because it is associated with deeperlevel strategic processing of information and more adaptive self-regulation (for review, see Schunk et al., 2014).

Prior research has also found that justification for knowing beliefs may be related to individual interest. For example, Strømsø and Bråten (2009) found that the more students believed that knowledge claims about a scientific topic need to be justified through rules of inquiry and the evaluation and integration of multiple sources, the more likely they were to be interested in that topic. Likewise, Bråten, Anmarkrud, et al. (2014) found that the more students believed in the importance or necessity of justifying knowledge claims in natural science by checking multiple external sources for consistency, the more interested they were in understanding science texts. However, to the best of our knowledge, previous research has 
not tested direct and indirect relationships between different justification beliefs in science, individual interest in a scientific topic, and knowledge about the topic.

\section{The Present Study}

Based on theoretical assumptions and prior research, we developed the model shown in Figure 1. The fit of this hypothesized model to data was tested in a sample of Norwegian upper secondary school students. This is the first study that investigates different types of justification for knowing constructs as predictors of topic interest and topic knowledge, including how topic interest may mediate the effects of different justification constructs on topic knowledge. Of note is also that our dependent measures of knowledge about climate change and nuclear power were previously validated knowledge tests developed in collaboration with independent experts in those areas (see Materials below). Finally, we tested our model across two topics (i.e., climate change and nuclear power), which also adds to the novelty of this empirical work. While previous studies in this area have included only one topic, targeting both climate change and nuclear power allowed us to probe the generalizability of our findings across two different scientific topics of great societal importance. Taken together, these aspects of the current study show that it represents a unique extension of prior work in the area that may have theoretical as well as educational implications. While the scientific understanding of climate change is widely accepted among young people in Norway, there is still considerable controversy concerning viable solutions (e.g., technological solutions vs. extensive societal changes). With respect to nuclear power, the resistance to this energy form is generally strong in Norway, with controversy concerning whether Norway should engage in further research on nuclear power (Stenseth, Bråten, \& Strøms $\varnothing, 2016)$.

[Figure 1 about here] 
As can be seen in Figure 1, interest in the topic was hypothesized to have a direct positive effect on students' knowledge about the topic. This assumption was grounded in much prior theoretical and empirical work linking interest to performance (Schunk et al., 2014). Further, we hypothesized that the interest variable, in turn, would be directly affected by beliefs in personal justification and justification by multiple sources. The effects of these two justification variables on knowledge were thus assumed to be mediated by topic interest. These assumptions are consistent with several theoretical models conceptualizing epistemic beliefs as contributors to various motivation constructs (Barger \& Linnenbrink-Garcia, 2017; Buehl, 2003; Hofer \& Pintrich, 1997; Muis, 2007), as well as with prior empirical work linking beliefs about justification for knowing to individual interest (Bråten, Anmarkrud, et al., 2014; Strømsø \& Bråten, 2009). Specifically, we hypothesized that personal justification had a direct negative effect on topic interest whereas justification by multiple sources had a direct positive effect. To the extent that students believe claims in science to be justified by personal opinion, it seems reasonable to expect that they will be less attracted by and engaged in complex scientific topics. This is because students relying on personal justification may be more likely to trust their own preconceptions about a controversial scientific topic without bothering to engage with the issue in order to develop a well-reasoned position (cf., Bråten, Strøms $\varnothing, \&$ Samuelstuen, 2008). Moreover, to the extent that students believe claims in science to be justified by checking multiple external information sources for consistency, it seems reasonable to expect that they will be more attracted by and engaged in such topics. This is because students relying on justification by multiple sources may be more likely to view a controversial scientific topic as an intriguing puzzle to be figured out through engagement and involvement with the topic (cf., Richards, Conlin, Gupta, \& Elby, 2013).

We also hypothesized that personal justification and justification by multiple sources had direct effects on knowledge about the scientific topic. These assumptions about direct 
effects were grounded in theory linking epistemic beliefs not only indirectly, but also directly, to performance (Buehl, 2003), as well as in empirical evidence suggesting that justification beliefs falling on these two dimensions may uniquely predict performance when controlling for other motivational and cognitive variables (Bråten et al., 2013; Bråten, Ferguson, Anmarkrud, et al., 2014). Specifically, on the basis of this research, we expected that beliefs in personal justification would directly and negatively affect topic knowledge. In contrast, beliefs in justification by multiple sources were expected to directly and positively affect topic knowledge. Given previous inconsistent findings with respect to beliefs in justification by

authority (see above), we were not able to specify the direction of any indirect or direct effect this variable might have on topic knowledge.

Finally, based on prior research on the trichotomous justification belief framework (Braasch et al., 2014; Bråten et al., 2013: Strømsø et al., 2016), we expected personal justification and justification by authority to be negatively correlated, while personal justification was expected to be positively correlated with justification by multiple sources. Presumably, students relying on internal, subjective means of justification are less likely to rely on an external authoritative (i.e., objective) source. Still, a substantial proportion of those who rely on personal justification may also search for and check various other sources in order to confirm or reinforce their preexisting views or opinions. We expected justification by an external authoritative source and justification by multiple sources to be negatively correlated. Presumably, students who rely on an external authoritative source do not feel the need to consult additional sources to evaluate knowledge claims.

\section{Method}

\section{Participants}

Participants were 281 students (54\% male) from 12 classes at a large public upper secondary school in southeast Norway with an overall mean age of 17.1 years $(S D=.68)$. In 
Norway, compulsory schooling begins at age 6 and lasts for 10 years. Upper secondary education lasts for 3 years and is non-compulsory. It comprises courses leading to qualifications above the compulsory lower secondary level but below the level of higher education. All participating students were completing college preparatory courses, with 58\% attending the second year and $42 \%$ attending the third year of upper secondary school. The majority (80\%) were born in Norway and learned Norwegian as their first language, and the rest were bilingual, raised in Norway, but with parents from different parts of the world. All materials were therefore in Norwegian. The sample was relatively homogenous with respect to socio-economic status (i.e., middle class). Collection and handling of all data in the current study met the requirements of the Personal Data Registers Act and were approved by the Norwegian Social Science Data Services.

\section{Materials}

Justification belief measures. The Justification for Knowing Questionnaire (JFK-Q) was used to assess beliefs about justification for knowing in the domain of science. This measure was initially described by Bråten et al. (2013) and Ferguson et al. (2013), and has later been used and validated in several studies (e.g., Ferguson \& Bråten, 2013; Trevors et al., 2017). It consists of 18 items written to assess three dimensions of justification for knowing: personal justification, justification by authority, and justification by multiple sources. The items targeting personal justification focus on the extent to which students consider it appropriate to evaluate knowledge claims on the basis of personal views or opinions. The higher students score on this dimension, the more they can be assumed to believe that knowledge claims in science can be justified by appealing to subjective, internal means of justification (sample item: If I think that something is correct in natural science, then no one can prove that I am wrong). The items targeting justification by authority focus on the credibility of claims based on scientific research and conveyed by teachers, textbooks, and 
scientists. The higher they score on this dimension, the more students can be assumed to believe that knowledge claims in science can be justified by appealing to an authoritative external source or scientific methodology (sample item: If a scientist says that something is a fact, then I believe it). Finally, the items targeting justification by multiple sources concern the extent to which students believe it is necessary to cross-check and corroborate claims across several information sources. Higher scores on this dimension can thus be assumed to represent stronger beliefs in the importance or necessity of justifying knowledge claims in science by checking multiple external sources for consistency (sample item: To be able to trust knowledge claims in natural science texts, I have to check various knowledge sources).

Students rated each item on a 10-point anchored rating scale $(1=$ disagree completely, $10=$ agree completely). For further information regarding dimensionality and reliability estimates in the present sample, see the Results section below.

Topic interest measures. We assessed individual interest and engagement in the topic of climate change with a 12-item measure that has been used and validated in prior research (Bråten, Gil, Strømsø, \& Vidal-Abarca, 2009; Strømsø, Bråten, \& Britt, 2010). On this measure, students indicated how interested or engaged they were in the topic of climate change by rating each item on a 10-point anchored scale $(1=$ not at all true of me, $10=$ very true of $m e$ ). Six of the items concerned interest in the topic without targeting active engagement or involvement on the part of the students (sample item: I am interested in international climate issues), while the other six items focused more on how engaged and involved they were in the topic and, thus, targeted to what extent students were willing to act for the benefit of the Earth's climate (sample item: I try to convince others that we should reduce the discharge of greenhouse gases). The internal consistency reliability (Cronbach's $\alpha$ ) for students' scores on the 12-item topic interest measure concerning climate change was .94. 
We assessed students' individual interest and engagement in the topic of nuclear power with a parallel 12-item measure that used an identical 10-point anchored rating scale. This topic interest measure also has been used and validated in prior research (McCrudden, Stenseth, Bråten, \& Strømsø, 2016; Stenseth et al., 2016). On six of the items, students just indicated how interested they were in issues concerning nuclear power (sample item: I am interested in issues concerning the safety of nuclear power plants), while the six other items focused more on the extent to which they were actively engaged and involved in the topic (sample item: I can imagine being a member of an organization working with issues concerning the use of nuclear power). The internal consistency reliability (Cronbach's $\alpha$ ) for students' scores on the 12-item topic interest measure concerning nuclear power was .90 .

Topic knowledge measures. A previously used and validated 15 -item multiple-choice measure was used to assess topic knowledge about climate change (e.g., Bråten et al. 2009; Bråten, Strøms $\varnothing$, \& Salmerón, 2011; Strøms $\varnothing$ et al., 2010). This measure contained items central to the topic of climate change (e.g., climate gases, global warming, the greenhouse effect, the Kyoto Protocol) and assessed to what extent students had established accurate factual and conceptual knowledge about this topic. Also, the measure covered scientific (e.g., climate gases) as well as political (e.g., the Kyoto Protocol) aspects of climate change. A climate researcher at the University of Oslo, who was not part of the project, carefully checked the response alternatives (i.e., the correct choice and the distractors) for each item. Students' scores were the number of correct responses. Test-retest reliability was estimated with an independent sample of first-year undergraduate students $(n=56)$, with the test and the retest administered two weeks apart. This resulted in a test-retest reliability (Pearson's $r$ ) of .77.

In addition, we administered a parallel 15-item multiple-choice measure targeting knowledge about nuclear power, which also has been used and validated in prior research 
(McCrudden et al., 2016; Stenseth et al., 2016). This topic knowledge measure included items that were central to the topic of nuclear power (e.g., nuclear power plants, nuclear fission, radioactive waste, the International Atomic Energy Agency) and assessed to what extent students had established accurate factual and conceptual knowledge about this topic. The measure covered both scientific (e.g., nuclear power plants) and political (e.g., the International Atomic Energy Agency) aspects of nuclear power. A nuclear physicist at the University of Oslo, who was not part of the project, carefully checked the response alternatives (i.e., the correct choice and the distractors) for each item. Students' scores were the number of correct responses. Test-retest reliability was estimated in an independent sample of third-year upper-secondary students $(n=82)$, with the test and the retest administered two weeks apart. This resulted in a test-retest reliability (Pearson's $r$ ) of .72. Sample items for both topic knowledge measures are included in the Appendix.

\section{Procedure}

The authors and four trained research assistants group administered the measures on paper in students' ordinary classrooms. After having completed a demographic survey and the justification belief measures, students completed the topic interest and the topic knowledge measure in that order for one of the topics and then for the other, with the order of the two topics counterbalanced. All completed the materials during an ordinary 45-min class period.

\section{Analytic Approach}

We used structural equation modeling with Mplus 7 (Muthén \& Muthén, 2012) to test our hypothesized model for each of the topics separately. To test the mediated effects of personal justification and justification by multiple sources that we hypothesized, we used the model command "indirect" in the Mplus 7 software. Considering the analytic situation with respect to sample size, number of parameters to be estimated, reliability estimates, and previous use of the measures, as well as a need to reduce model complexity (Brown, 2015; 
Ding, Velicer, \& Harlow, 1995), we decided to use a combination of latent and composite score variables. Initially, we examined the dimensionality of scores on the justification belief and topic interest measures by means of confirmatory factor analyses (CFA), which formed the basis for a well-fitted measurement model of justification beliefs and separate composite score measures for topic interest about climate change and nuclear power, respectively.

To assess the overall fit of a model, we used common estimates reported in Mplus 7: the chi-square statistics (non-significant estimates indicate very good fit), the comparative fit index (CFI), the root mean square error of approximation (RMSEA), and the standardized root mean square residual (SRMR). After reviewing the literature concerning cut-off criteria for goodness of fit (Bentler, 1990; Bentler \& Bonett, 1980; Hu \& Bentler, 1998, 1999; Marsh, Hau, \& Wen, 2004; Schermelleh-Engel, Moosbrugger, \& Müller, 2003), and taking the current analytic situation (e.g., model complexity) into consideration, we adopted the following criteria for model evaluation: $\mathrm{CFI} \geq .90, \mathrm{RMSEA} \leq .08$, and $\mathrm{SRMR} \leq .09$ indicate an acceptable fit of the model, while CFI $\geq .95$, RMSEA $\leq .05$, and $\mathrm{SRMR} \leq .06$ indicate a good model fit.

\section{Results}

\section{Preliminary Analyses}

A three-factor CFA model of justification beliefs including all 18 items of the JFK-Q did not result in an acceptable fit to the data, $\chi^{2}[132]=386, p<.001 ; \mathrm{CFI}=.77 ; \mathrm{RMSEA}=$ $.083,90 \%$ CI $[.073-.093] ;$ SRMR $=.103$. We therefore respecified and reevaluated the model based on factor solutions obtained in previous research (Bråten, Ferguson, Anmarkrud, et al., 2014; Ferguson et al., 2013). The final measurement model, which included 12 items, fit the data well, $\chi^{2}[51]=94, p<.001 ; \mathrm{CFI}=.95 ; \mathrm{RMSEA}=.055,90 \%$ CI $[.037-.072]$; SRMR $=.056$. In this model, four items were included in the justification by authority factor, five in the justification by multiple sources factor, and three in the personal justification 
factor. Reliability estimates are shown in Table 1 . The reliability for personal justification was somewhat lower than desirable, presumably due to the small number of items included in this factor. Still, a reliability of .62 is comparable to that obtained in prior work (Ferguson \& Bråten, 2014; Ferguson et al., 2013). Moreover, several methodologists (e.g., Hair, Black, Babin, Anderson, \& Tatham, 2006; Kerlinger \& Lee, 2000) have argued that such an estimate may be acceptable if measures are used in group-based research and not for making consequential decisions about individual students. Of note is that not only the three factors that we obtained in the current study, but also the items that loaded on each factor, were consistent with the results of prior factor analyses of the JFK-Q (Bråten, Ferguson, Anmarkrud, et al., 2014; Ferguson et al., 2013).

\section{[Table 1 about here]}

With respect to the interest measures, we tested a two-factor CFA model including all 24 items, with the two factors concerning interest in climate change (12 items) and nuclear power (12 items), respectively. We included interest in both climate change and nuclear power in this CFA to try to confirm that they really represented two distinct topic interest constructs. The initial model did not result in an acceptable fit to the data, $\chi^{2}[251]=819, p<$ $.001 ; \mathrm{CFI}=.84 ; \mathrm{RMSEA}=.090,90 \% \mathrm{CI}[.083-.097] ; \mathrm{SRMR}=.079$. The modification indices suggested that two of the nuclear power interest items loaded on the climate change interest factor, and that five parallel items had common error variance across the two factors. These suggestions for modification were reasonable from a substantial point of view because the cross-loadings were related to policy interest and the common error variance for the parallel items was related to similarity in wordings. We therefore tested a modified model allowing the two first-mentioned items to cross-load and the five parallel items to correlate. The modified model had an acceptable fit to the data, $\chi^{2}[244]=602, p<.001 ; \mathrm{CFI}=.90$; $\mathrm{RMSEA}=.072,90 \% \mathrm{CI}[.065-.080] ; \mathrm{SRMR}=.065$, indicating that the interest measures 
represented two distinct topic interest constructs that could be used to test our hypothesized model for climate change and nuclear power separately. Due to the complexity of the estimation (the CFA interest model had 80 freely estimated parameters alone) and the fact that the reliability estimates for both interest measures were very high, we used composite-score interest measures in testing the hypothesized model. These composite scores were computed by dividing the scores for all items by the number of items so that the scores potentially ranged from 1 to 10. For the topic knowledge measures, composite scores were computed by adding the correct number of responses to the multiple-choice items so that the scores potentially ranged from 0 to 15 .

Descriptive statistics and reliabilities for all constructs involved in the final model testing are displayed in Table 1, together with zero-order correlations between those constructs. Of note is that students' interest in climate change was higher than their interest in nuclear power, $t(276)=18.39, p<.001$, Cohen's $d=0.88$. There was also a small but statistically significant difference between the knowledge scores indicating that students had more knowledge about climate change issues than about nuclear power issues, $t(280)=2.98$, $p<.01$, Cohen's $d=0.18$.

\section{Hypothesized Model Testing}

We first tested the hypothesized model for the topic of climate change (see Figure 1). The fit indices indicated an acceptable fit of the model, $\chi^{2}[69]=124, p<.001 ; \mathrm{CFI}=.94$; $\mathrm{RMSEA}=.053,90 \% \mathrm{CI}[.038-.068] ; \mathrm{SRMR}=.055$ As expected, there was a direct positive effect of topic interest on topic knowledge $(\beta=.21, p<.001)$, and beliefs in justification by multiple sources had, in turn, a direct positive effect on topic interest $(\beta=.24, p<.001)$. Also as expected, there was a mediated effect of justification by multiple sources on topic knowledge via topic interest $(\beta=.05, p=.01)$. There was no statistically significant direct effect of beliefs in personal justification on topic interest, however $(\beta=-.11, p=.18)$, and 
hence no mediated effect of personal justification on topic knowledge. Topic knowledge was directly affected by beliefs in justification by multiple sources $(\beta=.12, p<.05)$ and personal justification $(\beta=-.22, p<.001)$. As expected, personal justification had a direct negative effect whereas justification by multiple sources had a direct positive effect on topic knowledge. Finally, beliefs in justification by authority did not have any statistically significant direct effect on topic knowledge $(\beta=.06, p=.43)$ or topic interest $(\beta=-.11, p=$ .11). Taken together, the justification belief variables explained $8 \%$ of the variance in topic interest, and the model explained $13 \%$ of the variance in topic knowledge.

[Figure 2 about here]

Testing the hypothesized model for the topic of nuclear power also resulted in an acceptable fit of the model, $\chi^{2}[69]=120, p<.001 ; \mathrm{CFI}=.94 ; \mathrm{RMSEA}=.052,90 \%$ CI $[.036$ $-.067]$; SRMR $=.055$. This model is displayed in Figure 3. Again, there was a direct positive effect of topic interest on topic knowledge $(\beta=.31, p<.001)$, and beliefs in justification by multiple sources had, in turn, a direct positive effect on topic interest $(\beta=.25, p<.001)$. Thus, consistent with our expectation, there was a mediated effect of justification by multiple sources on topic knowledge via topic interest $(\beta=.08, p<.01)$. There was no statistically significant direct effect of beliefs in personal justification on topic interest, however $(\beta=-.12$, $p=.16$ ), and hence no mediated effect of personal justification on topic knowledge. For this topic, the direct effect of justification by multiple sources $(\beta=.09, p=.19)$ or personal justification $(\beta=-.15, p=.09)$ on topic knowledge was also not statistically significant. More of the expected effects thus reached statistical significance for climate change than for nuclear power. Still, the valences of all these effects were in the expected direction for nuclear power. As for climate change, beliefs in justification by authority did not have any statistically significant direct effect on topic knowledge $(\beta=-.04, p=.58)$ or topic interest $(\beta=-.08, p=$ 
.27). Taken together, the justification belief variables explained $8 \%$ of the variance in topic interest, and the model explained $14 \%$ of the variance in topic knowledge.

[Figure 3 about here]

\section{Discussion}

This is an era where an almost infinite amount of unvetted information on almost any topic is just a mouse-click away (Magilano, McCrudden, Rouet, \& Sabatini, 2018). Therefore, trying to understand individual factors that underlie students' building of accurate factual and conceptual knowledge about controversial socio-scientific issues seems like a worthwhile

educational enterprise (Sinatra et al., 2014; Trevors et al., 2017). In the present study, we built on scholarship within personal epistemology (Greene et al., 2008, 2010; Ferguson et al., 2012, 2013) and assumed that one such factor would be students' beliefs about the justification for knowing in science, in particular their beliefs regarding justification by personal opinion and justification by multiple external sources. Moreover, we assumed that in addition to having direct effects on students' topic knowledge, beliefs in personal justification and justification by multiple sources would indirectly affect topic knowledge through their influence on topic interest.

Our assumptions regarding justification by multiple sources were largely supported in the present study. Thus, with respect to climate change, this variable had direct as well as indirect positive effects on topic knowledge, and with respect to nuclear power, it indirectly (but not directly) had a positive effect on students' knowledge. While the direct positive effect that was found for climate change is consistent with prior work within the trichotomous justification belief framework (Ferguson et al., 2012, 2013), the finding that justification by multiple sources may work through topic interest provides new evidence about the adaptive role of such epistemic beliefs. Thus, to the extent that students believe that justification of knowledge claims in science relies on comparing and cross-checking several sources of 
information, they also seem more likely to develop interest for the topics in question. In turn, such topic interest may provide impetus for building a reliable knowledge base with respect to those topics. Although they have not focused on justification by multiple sources and topic interest in particular, this finding also gains credence by being consistent with several conceptualizations highlighting potential indirect effects of epistemic beliefs on performance via motivation (Barger \& Linnenbrink-Garcia, 2017; Buehl, 2003; Hofer \& Pintrich, 1997; Muis, 2007). Presumably, justification by multiple sources did not have a direct positive effect on knowledge about nuclear power because knowledge about this topic was more strongly predicted by topic interest. While this made it harder for justification by multiple sources to explain unique variance in topic knowledge about nuclear power, it may also have contributed to a stronger indirect effect of justification by multiple sources for this topic.

Regarding the mechanism by which justification by multiple sources can contribute to topic interest, one possibility is that this way of justification in science translates into viewing controversial science topics as complex puzzles to be solved by collecting, comparing, and combining several pieces of evidence. Consequentially, individuals may become more attracted to and engaged in such topics. Although somewhat speculative, this possibility finds some support in qualitative work suggesting that viewing science as something that has to be figured out may spark engagement and persistence when dealing with challenging scientific topics (Richards et al., 2013).

More limited support was found for our assumptions regarding personal justification in this study. Thus, while the pattern of prediction was consistent with our expectations for both topics, only the direct negative effect on topic knowledge about climate change was statistically significant. In particular, the weaker relationships between personal justification and interest in both topics suggest that stronger beliefs in personal justification of knowledge claims in science may not necessarily weaken students' interest in controversial socio- 
scientific topics. Still, beliefs in personal justification may have negative effects on students' knowledge generation regarding such topics, for example because it may lead to more superficial or biased processing of information presented by external sources (Bråten \& Ferguson, 2014). Given our findings, more research is needed to examine the extent to which personal justification has negative effects on accurate knowledge generation across various socio-scientific topics. Because our participants scored quite low on personal justification, we also cannot entirely rule out the possibility that floor effects might explain why some of the paths from this variable were not statistically significant in the current study.

Finally, beliefs in justification by authority were not found to be related to topic knowledge in this study, neither directly nor indirectly. Of note is that this measure included items referring to justification by a science teacher or a science textbook in addition to a scientist, and that scores on this measure also have been found to be unrelated to students' performance in prior work (Bråten et al., 2013). At the same time, however, when this belief dimension has been conceptualized more narrowly, addressing only justification by scientific authority (i.e., by a scientist or scientific research), it has been found to explain unique variance in students' science achievement (Bråten \& Ferguson, 2014). In further research on direct and indirect relationships between epistemic beliefs, topic interest, and topic knowledge, we therefore suggest that different types of justification by authority are included as separate dimensions in the same study, such as justification by a teacher, a textbook, and a scientist, respectively.

Among the limitations of the present study is that beliefs about justification for knowing were assessed with a questionnaire rather than "in action", for example through think-alouds and observations (Mason, 2016). To the extent that researchers attempt to capture how individuals respond to specific learning tasks by activating and deactivating finegrained epistemic resources, as described within the contextualized resource view of Elby and 
colleagues (Elby \& Hammer, 2010; Elby, Macrander, \& Hammer, 2016; Hammer \& Elby, 2002), such process-oriented methodologies are required. When trying to assess more stable epistemic beliefs, however, domain-specific or topic-specific self-report measures seem more appropriate (Bråten, 2016). In the current study, we acknowledged the domain-specific nature of epistemic beliefs by measuring beliefs about justification for knowing in science. However, another possibility is to study the relationships between the targeted constructs by using questionnaires addressing justification beliefs, interest, and knowledge at the same level of specificity, that is, by measuring justification beliefs with respect to the particular topics in question (Bråten et al., 2009). This is because measuring beliefs and the other constructs at the same level of specificity may strengthen the predictive relationships among them (Bråten et al., 2009; Pajares, 1996).

Moreover, questions about causality cannot be answered adequately by our crosssectional design using only correlational data. Thus, while the structural equation modeling that we performed comes with causal terminology and is often referred to as causal modeling, it should be acknowledged that our approach was suitable for testing predictive relationships but not revealing causes. As such, we cannot be sure about the direction of effects or rule out the possibility of bidirectional relationships among the constructs that we included in our model. For example, we cannot entirely rule out that topic interest or topic knowledge are predictors of justification beliefs in science. It may seem less likely that interest and knowledge at a topic-specific level underlie justification beliefs at a domain-specific level than the other way around, however, because justification beliefs concerning science in general may be considered to frame and guide the acquisition of interest and knowledge about specific topics. Of note is also that our reason for testing this particular relationship between variables was theoretical, with the assumption that epistemic beliefs underlie motivation and performance rather than vice versa being consistent with several theoretical models (Barger \& 
Linnenbrink-Garcia, 2017; Buehl, 2003; Hofer \& Pinrich, 1997; Muis, 2007). We

acknowledge, however, that longitudinal studies or experimental studies targeting justification beliefs and assessing changes in topic interest and topic knowledge are needed to discover causal relationships between these constructs. Preferably, such studies should test these relationships while assessing justification for knowing "in action" and using more extensive data on learning and performance. Despite the fact that participants had more knowledge about climate change than about nuclear power, this difference was quite small. Future research could therefore study direct and indirect effects of justification for knowing for a range of topics that differ more with respect to participants' level of knowledge.

In particular, research on efforts to change students' beliefs about justification for knowing is highly needed. Thus, while our study may suggest that instructional efforts to strengthen students' beliefs in justification by multiple sources and weaken their beliefs in personal justification, if successful, may have positive consequences in terms of interest and knowledge generation, this suggestion needs further empirical backing. Using a unidimensional approach to measuring justification beliefs that built on Hofer and Pintrich's (1997) conceptualization, Muis and Duffy (2013) found that undergraduates' beliefs about justification for knowing changed during a one-semester intervention. This intervention took place in statistics class and involved constructivist teaching practices. Importantly, concomitant changes in students' perceived self-efficacy also occurred during this intervention. In a much shorter intervention study, Ferguson et al. (2013) found that students who worked with multiple conflicting documents on a scientific topic strengthened their beliefs in justification by multiple sources and weakened their beliefs in personal justification, with concomitant changes observed in comprehension performance. Taken together, these studies suggest that justification beliefs may be changed through instructional interventions and that positive consequences in terms of motivation and performance may follow. However, 
to more directly assess the instructional implications suggested by the present study, future researchers should target different types of justification beliefs through instruction and observe the extent to which strengthening beliefs in justification by multiple sources and weakening beliefs in personal justification, in particular, will have expected consequences in terms of student interest and knowledge generation.

\section{Conclusion}

This study provides new evidence regarding the role of epistemic beliefs concerning the justification for knowing in students' knowledge construction. Specifically, it highlights the potentially positive role of beliefs in justification by multiple sources and the potentially negative role of beliefs in personal justification, with the former type of beliefs also likely to work through students' interest in the topics in question. Although these findings also may have practical implications, further experimental work aiming to modify different beliefs about justification for knowing is needed to test their educational relevance. Hopefully, this study will give impetus to such experimental work. 


\section{Note}

${ }^{1}$ In addition to dimensional models of personal epistemology (e.g., Hofer \& Pintrich, 1997; Schommer, 1990), which figure prominently within educational psychology, models within developmental psychology (e.g., Kuhn, Cheney, \& Weinstock, 2000; Perry, 1970) describe the development of people's views about the nature of knowledge and the nature of knowing in terms of sequential stages or phases. Developmental models fall outside the scope of the current study, however, which is grounded in an educational psychology dimensional view of personal epistemology, focusing on multiple dimensions of justification for knowing, in particular. 


\section{References}

Alexander, P.A. (1997). Mapping the multidimensional nature of domain learning: The interplay of cognitive, motivational, and strategic forces. In M.L. Maehr \& P.R. Pintrich (Eds.), Advances in motivation and achievement (Vol. 10, pp. 213-250). Greenwich, CT: JAI.

Alexander, P.A. (2012). Reading into the future: Competence for the 21 st century. Educational Psychologist, 47, 259-280.

Barger, M.M., \& Linnenbrink-Garcia, L. (2017). Developmental systems of students' personal theories about education. Educational Psychologist, 52, 63-83.

Bentler, P.M. (1990). Comparative fit indexes in structural models. Psychological Bulletin, 107, 238-246.

Bentler, P.M., \& Bonett, D.G. (1980). Significance tests and goodness of fit in the analysis of covariance structures. Psychological Bulletin, 88, 588-606.

Braasch, J.L.G., Bråten, I., Britt, M.A., Steffens, B., \& Strømsø, H.I. (2014). Sensitivity to inaccurate argumentation in health news articles: Potential contributions of readers' topic and epistemic beliefs. In D.N. Rapp \& J.L.G. Braasch (Eds.), Processing inaccurate information: Theoretical and applied perspectives from cognitive science and the educational sciences (pp. 117-137). Cambridge, MA: MIT Press.

Bråten, I. (2016). Epistemic cognition interventions: Issues, challenges, and directions. In J.A. Greene, W.A. Sandoval, \& I. Bråten (Eds.), Handbook of epistemic cognition (pp. 360-371). New York: Routledge.

Bråten, I., Anmarkrud, Ø., Brandmo, C., \& Strømsø, H.I. (2014). Developing and testing a model of direct and indirect relationships between individual differences, processing, and multiple-text comprehension. Learning and Instruction, 30, 9-24.

Bråten, I., \& Ferguson, L.E. (2014). Investigating cognitive capacity, personality, and 
epistemic beliefs in relation to science achievement. Learning and Individual Differences, 36, 124-130.

Bråten, I., Ferguson, L.E., Anmarkrud, Ø., Strømsø, H.I., \& Brandmo, C. (2014). Modeling relations between students' justification for knowing beliefs in science, motivation for understanding what they read in science, and science achievement. International Journal of Educational Research, 66, 1-12.

Bråten, I., Ferguson, L.E., Strømsø, H.I., \& Anmarkrud, Ø. (2013). Justification beliefs and multiple-documents comprehension. European Journal of Psychology of Education, 28, 879-902.

Bråten, I., Ferguson, L.E., Strømsø, H.I., \& Anmarkrud, Ø. (2014). Students working with multiple conflicting documents on a scientific issue: Relations between epistemic cognition while reading and sourcing and argumentation in essays. British Journal of Educational Psychology, 84, 58-85.

Bråten, I., Gil, L., Strømsø, H.I., \& Vidal-Abarca, E. (2009). Personal epistemology across cultures: Exploring Norwegian and Spanish university students' epistemic beliefs about climate change. Social Psychology of Education, 12, 529-560.

Bråten, I., \& Strømsø, H.I. (2010). When law students read multiple documents about global warming: Examining the role of topic-specific beliefs about the nature of knowledge and knowing. Instructional Science, 38, 635-657.

Bråten, I., Strømsø, H.I., \& Salmerón, L. (2011). Trust and mistrust when students read multiple information sources about climate change. Learning and Instruction, 21, 180192.

Bråten, I., Strømsø, H.I., \& Samuelstuen, M.S. (2005). The relationship between Internetspecific epistemological beliefs and learning within Internet technologies. Journal of Educational Computing Research, 33, 141-171. 
Bråten, I., Strøms $\varnothing$, H.I., \& Samuelstuen, M.S. (2008). Are sophisticated students always better? The role of topic-specific personal epistemology in the understanding of multiple texts. Contemporary Educational Psychology, 33, 814-840.

Bromme, R., \& Goldman, S.R. (2014). The public's bounded understanding of science. Educational Psychologist, 49, 59-69.

Brown, T.A. (2015). Confirmatory factor analysis for applied research (2 ed.). New York: Guilford.

Buehl (2003). At the crossroads of epistemology and motivation: Modeling the relations between students' domain-specific epistemological beliefs, achievement motivation, and task performance. Doctoral dissertation, University of Maryland. Retrieved March 5, 2013 from http://drum.lib.umd.edu/bitstream/1903/317/1/dissertation.pdf

Chen, J.A., \& Barger, M.M. (2016). Epistemic cognition and motivation. In J.A. Greene, W.A. Sandoval, \& I. Bråten (Eds.), Handbook of epistemic cognition (pp. 425-438). New York: Routledge.

Chiu, Y.-L., Liang, J.-C., \& Tsai., C.-C. (2013). Internet-specific beliefs and self-regulated learning in online academic information searching. Metacognition and Learning, 8, 235-260.

Conley, A.M., Pintrich, P.R., Vekiri, I., \& Harrison, D. (2004). Changes in epistemological beliefs in elementary science students. Contemporary Educational Psychology, 29, 186-204.

Ding, L., Velicer, W.F., \& Harlow, L.L. (1995). Effects of estimation methods, number of indicators per factor, and improper solutions on structural equation modeling fit indices. Structural Equation Modeling: A Multidisciplinary Journal, 2, 119-143.

Elby, A., \& Hammer, D. (2010). Epistemological resources and framing: A cognitive framework for helping teachers interpret and respond to their students' epistemologies. 
In L. Bendixen \& F.C. Feucht (Eds.), Personal epistemology in the classroom: Theory, research, and implications for practice (pp. 409-434). Cambridge, UK: Cambridge University Press.

Elby, A., Macrander, C., \& Hammer, D. (2016). Epistemic cognition in science. In J.A. Greene, W.A. Sandoval, \& I. Bråten (Eds.), Handbook of epistemic cognition (pp. 113-127). New York: Routledge.

Ferguson, L.E., \& Bråten, I. (2013). Student profiles of knowledge and epistemic beliefs: Changes and relations to multiple-text comprehension. Learning and Instruction, 25, 49-61.

Ferguson, L.E., Bråten, I., \& Strømsø, H.I. (2012). Epistemic cognition when students read multiple documents containing conflicting scientific evidence: A think-aloud study. Learning and Instruction, 22, 103-120.

Ferguson, L.E., Bråten, I., Strømsø, H.I., \& Anmarkrud, Ø. (2013). Epistemic beliefs and comprehension in the context of reading multiple documents: Examining the role of conflict. International Journal of Educational Research, 62, 100-114.

Greene, J.A., Azevedo, R., \& Torney-Purta, J. (2008). Modeling epistemic and ontological cognition: Philosophical perspectives and methodological directions. Educational Psychologist, 43, 142-160.

Greene, J.A., Torney-Purta, J., \& Azevedo, R. (2010). Empirical evidence regarding relations among a model of epistemic and ontological cognition, academic performance, and educational level. Journal of Educational Psychology, 102, 234-255.

Greene, J.A., Yu, S.B., \& Copeland, D.Z. (2014). Measuring critical components of digital literacy and their relationships with learning. Computers \& Education, 76, 55-69.

Hair, J., Black, W., Babin, B., Anderson, R., \& Tatham, R. (2006). Multivariate data analysis (6th ed.). Upper Saddle River, NJ: Pearson. 
Hammer, D., \& Elby, A. (2002). On the form of a personal epistemology. In B.K. Hofer \& P. R. Pintrich (Eds.), Personal epistemology: The psychology of beliefs about knowledge and knowing (pp. 169-190). Mahwah, NJ: Erlbaum.

Hidi, S., \& Renninger, K.A. (2006). The four-phase model of interest development. Educational Psychologist, 41, 111-127.

Hofer, B.K., \& Bendixen, L.D. (2012). Personal epistemology: Theory, research, and future directions. In K.R. Harris, S. Graham, \& T. Urdan (Eds.), APA Educational Psychology Handbook: Vol. 1. Theories, constructs, and critical issues (pp. 227-256). Washington, DC: American Psychological Association.

Hofer, B.K., \& Pintrich, P.R. (1997). The development of epistemological theories: Beliefs about knowledge and knowing and their relation to learning. Review of Educational Research, 67, 88-140.

Hu, L.T., \& Bentler, P.M. (1998). Fit indices in covariance structure modeling: Sensitivity to underparameterized model misspecification. Psychological Methods, 3, 424-453.

Hu, L.T., \& Bentler, P.M. (1999). Cutoff criteria for fit indexes in covariance structure analysis: Conventional criteria versus new alternatives. Structural Equation Modeling: A Multidisciplinary Journal, 6, 1-55.

Kammerer, Y., Amann, D.G., \& Gerjets, P. (2015). When adults without university education search the Internet for health information: The roles of Internet-specific epistemic beliefs and a source evaluation intervention. Computers in Human Behavior, 48, $297-$ 309.

Kammerer, Y., Bråten, I., Gerjets, P., \& Strømsø, H.I. (2013). The role of Internet-specific epistemic beliefs in laypersons' source evaluations and decisions during Web search on a medical issue. Computers in Human Behavior, 29, 1193-1203.

Kendeou, P., Braasch, J.L.G., \& Bråten, I. (2016). Optimizing conditions for learning: 
Situating refutations in epistemic cognition. Journal of Experimental Education, 84, 245-263.

Kerlinger, F.N., \& Lee, H.B. (2000). Foundations of behavioral research (4th ed.). Forth Worth, TX: Harcourt College Publishers.

Kuhn, D., Cheney, R., \& Weinstock, M. (2000). The development of epistemological understanding. Cognitive Development, 15, 309-328.

Lee, W.-C., Chiu, Y.-L., Liang, J.-C., \& Tsai, C.-C. (2014). Exploring the structural relationships between high school students` Internet-specific epistemic beliefs and their utilization of online academic help seeking. Computers in Human Behavior, 36, 391-400.

Magliano, J.P., McCrudden, M.T., Rouet, J.F., \& Sabatini, J. (2018). The modern reader: Should changes to how we read affect research and theory? In M.F. Schober, D.N. Rapp, \& M.A. Britt (Eds.), Handbook of discourse processes (2nd ed., pp. 343-361). New York: Routledge.

Marsh, H.W., Hau, K.T., \& Wen, Z. (2004). In search of golden rules: Comment on hypothesistesting approaches to setting cutoff values for fit indexes and dangers in overgeneralizing Hu and Bentler's (1999) findings. Structural Equation Modeling: A Multidisciplinary Journal, 11, 320-341.

Mason, L. (2016). Psychological perspectives on measuring epistemic cognition. In J.A. Greene, W.A. Sandoval, \& I. Bråten (Eds.), Handbook of epistemic cognition (pp. 375-392). New York: Routledge.

Mason, L., Ariasi, N., \& Boldrin, A. (2011). Epistemic beliefs in action: Spontaneous reflections about knowledge and knowing during online information searching and their influence on learning. Learning and Instruction, 21, 137-151.

Mason, L., Boldrin, A., \& Ariasi, N. (2010). Searching the Web to learn about a controversial topic: Are students epistemically active? Instructional Science, 38, 607-633. 
McCrudden, M.T., Stenseth, T., Bråten, I., \& Strømsø, H.I. (2016). The effects of author expertise and content relevance on document selection: A mixed methods study. Journal of Educational Psychology, 108, 147-162.

Muis, K.R. (2007). The role of epistemic beliefs in self-regulated learning. Educational Psychologist, 42, 173-190.

Muis, K.R. (2008). Epistemic profiles and self-regulated learning: Examining relations in the context of mathematics problem solving. Contemporary Educational Psychology, 33, 177-208.

Muis, K.R., Bendixen, L.D., \& Haerle, F.C. (2006). Domain-generality and domainspecificity in personal epistemology research: Philosophical and empirical reflections in the development of a theoretical framework. Educational Psychology Review, 18, 354.

Muis, K.R., \& Duffy, M.C. (2013). Epistemic climate and epistemic change: Instruction designed to change students' beliefs and learning strategies and improve achievement. Journal of Educational Psychology, 105, 213-225.

Muis, K.R., \& Franco, G. (2010). Epistemic profiles and metacognition: Support for the consistency hypothesis. Metacognition and Learning, 5, 27-45.

Muthén, L.K., \& Muthén, B. (2012). Mplus user's guide Version 7. Los Angeles, CA: Muthén \& Muthén.

Pajares, F. (1996). Self-efficacy beliefs in academic contexts. Review of Educational Research, 66, 543-578.

Perry, W.G. (1970). Forms of intellectual and ethical development in the college years: A scheme. New York: Holt, Rinehart \& Winston.

Pintrich, P.R. (2002). Future challenges and directions for theory and research on personal epistemology. In B.K. Hofer \& P.R. Pintrich (Eds.), Personal epistemology: The 
psychology of beliefs about knowledge and knowing (pp. 389-414). Mahwah, NJ: Erlbaum.

Richards, J., Conlin, L., Gupta, A., \& Elby, A. (2013). Coupling epistemology and identity in explaining student interest in science. In P.V. Engelhardt, A.D. Churukian, \& N.S. Rebello (Eds.), 2012 Physics Education Research Conference proceedings (pp. 334337). Philadelphia, PA: American Institute of Physics.

Schermelleh-Engel, K., Moosbrugger, H., \& Müller, H. (2003). Evaluating the fit of structural equation models: Tests of significance and descriptive goodness-of-fit measures. Methods of Psychological Research Online, 8(2), 23-74.

Schiefele, U. (1999). Interest and learning from text. Scientific Studies of Reading, 3, 257-279.

Schiefele, U. (2009). Situational and individual interest. In K.R. Wentzel \& A. Wigfield (Eds.), Handbook of motivation at school (pp. 197-222). New York: Routledge.

Schommer, M. (1990). Effects of beliefs about the nature of knowledge on comprehension. Journal of Educational Psychology, 82, 498-504.

Schunk, D.H., Meece, J.L., \& Pintrich, P.R. (2014). Motivation in education: Theory, research, and applications (4th ed.). Colombus, OH: Pearson Merrill Prentice Hall.

Sinatra, G.M., Kienhues, D., \& Hofer, B.K. (2014). Addressing challenges to public understanding of science: Epistemic cognition, motivated reasoning, and conceptual change. Educational Psychologist, 49, 123-138.

Stenseth, T., Bråten, I., \& Strøms $\varnothing$, H.I. (2016). Investigating interest and knowledge as predictors of students' attitudes towards socio-scientific issues. Learning and Individual Differences, 47, 274-280.

Strøms $\varnothing$, H.I., \& Bråten, I. (2009). Beliefs about knowledge and knowing and multiple-text comprehension among upper secondary students. Educational Psychology, 29, 425445 . 
Strøms $\varnothing$, H.I., \& Bråten, I. (2010). The role of personal epistemology in the self-regulation of Internet-based learning. Metacognition and Learning, 5, 91-111.

Strøms $\varnothing$, H.I., Bråten, I., Anmarkrud, Ø., \& Ferguson, L.E. (2016). Beliefs about justification for knowing when ethnic-majority and ethnic-minority students read multiple conflicting documents. Educational Psychology, 36, 638-657.

Strømsø, H.I., \& Bråten, I., \& Britt, M.A. (2010). Reading multiple texts about climate change: The relationship between memory for sources and text comprehension. Learning and Instruction, 18, 513-527.

Trevors, G.J., Kendeou, P., Bråten, I., \& Braasch, J.L.G. (2017). Adolescents’ epistemic profiles in the service of knowledge revision. Contemporary Educational Psychology, 49, 107-120.

Wigfield, A., \& Eccles, J.S. (2000). Expectancy-value theory of achievement motivation. Contemporary Educational Psychology, 25, 68-81. 
Table 1

Descriptive statistics, reliabilities, and zero-order correlations

\begin{tabular}{lllllllll}
\hline & 1 & 2 & 3 & 4 & 5 & 7 & 8 \\
\hline 1 & Justification by authority & - & & & & & & \\
2 & Justification by multiple sources & $-.19^{* *}$ & - & & & & & \\
3 & Personal justification & $-.34^{* * *}$ & .12 & - & & & \\
4 & Topic interest climate change & -.12 & $.19^{* * *}$ & -.05 & - & & \\
5 & Topic interest nuclear power & -.09 & $.22^{* * *}$ & -.06 & $.70^{* * *}$ & - & & \\
7 & Topic knowledge climate change & .09 & $.13^{*}$ & $-.24^{* * *}$ & $.24^{* * *}$ & $.29^{* * *}$ & - & \\
8 & Topic knowledge nuclear power & -.03 & $.15^{*}$ & -.15 & $.20^{* * *}$ & $.33^{* * *}$ & $.51^{* * *}$ & - \\
& Reliability & $.85^{1}$ & $.78^{1}$ & $.62^{1}$ & $.94^{1}$ & $.90^{1}$ & $.77^{2}$ & $.72^{2}$ \\
& Means & 7.13 & 6.88 & 2.74 & 5.40 & 3.75 & 7.82 & 7.35 \\
& Standard deviation & 1.93 & 1.90 & 1.61 & 2.05 & 1.69 & 2.56 & 2.72 \\
\hline
\end{tabular}

Note: $* p<.05, * * p<.01, * * * p<.001 .{ }^{1}$ Cronbach's $\alpha,{ }^{2}$ test- retest reliability. 


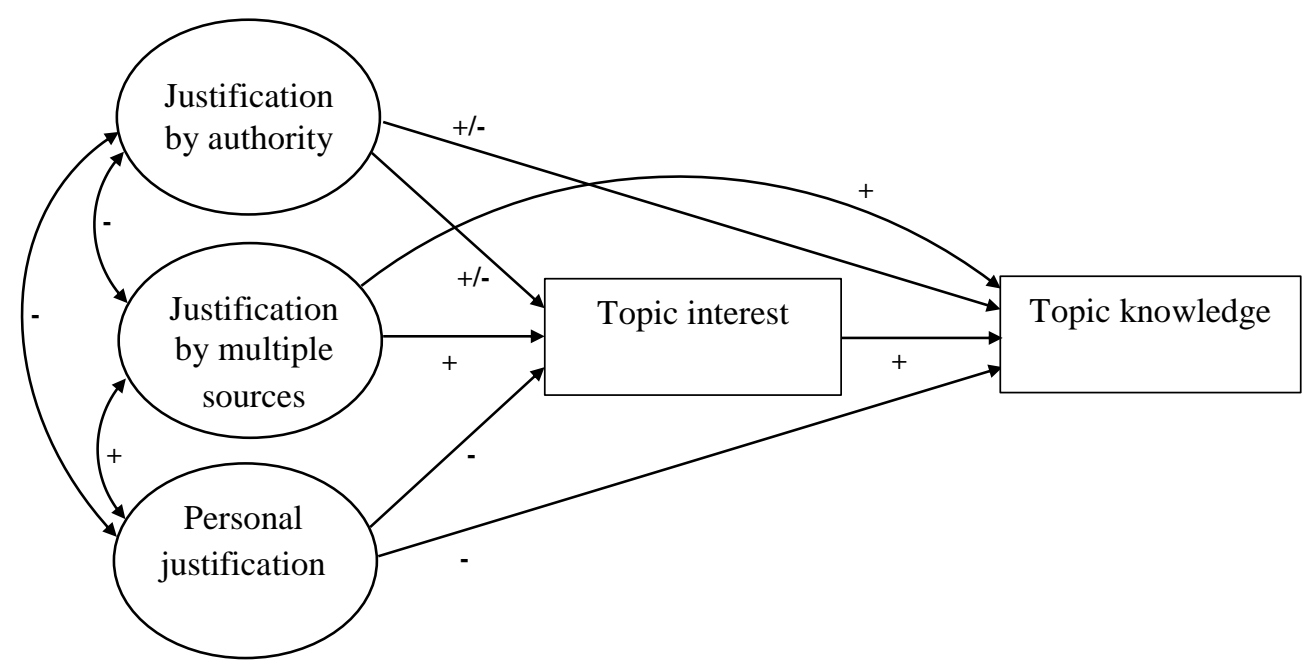

Figure 1

The hypothesized model. $+=$ positive prediction, $-=$ negative prediction, $+/-=$ valence not prespecified. 


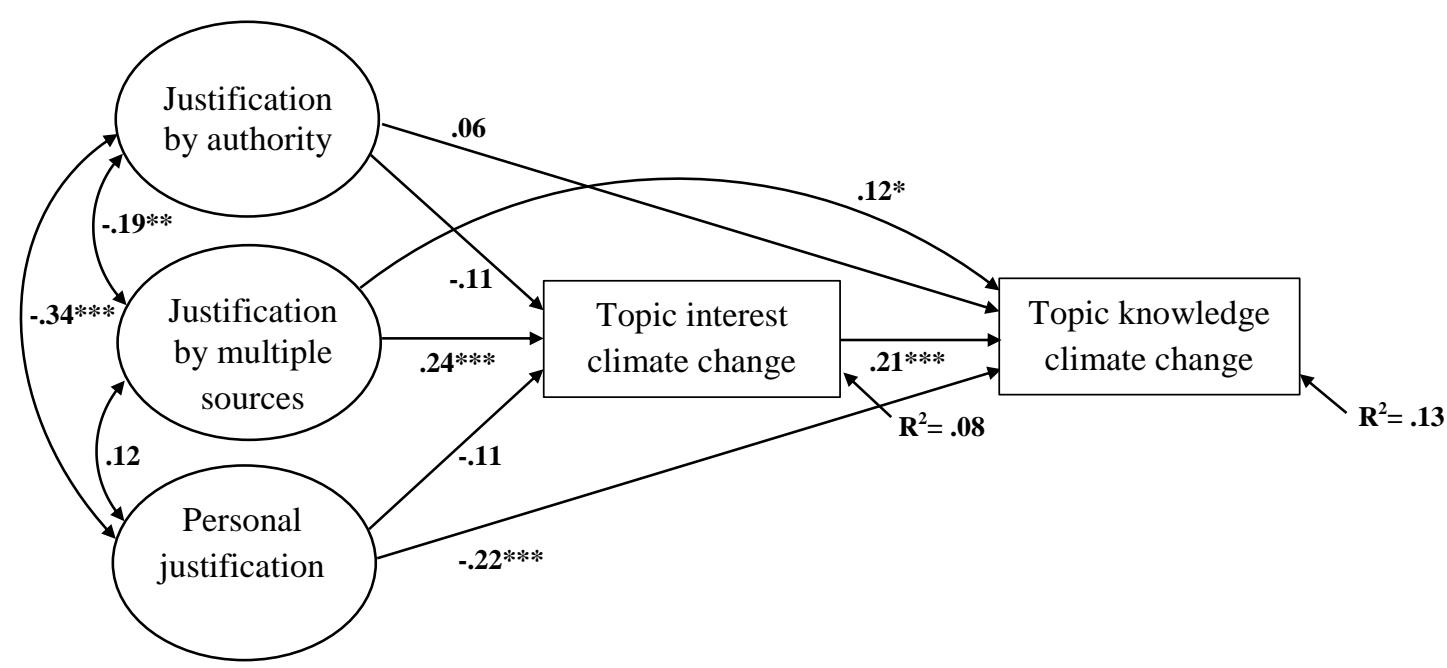

Figure 2

The model for climate change with standardized path coefficients and explained variance in the prediction of dependent variables. $* p<.05, * * p<.01, * * * p<.001$. 


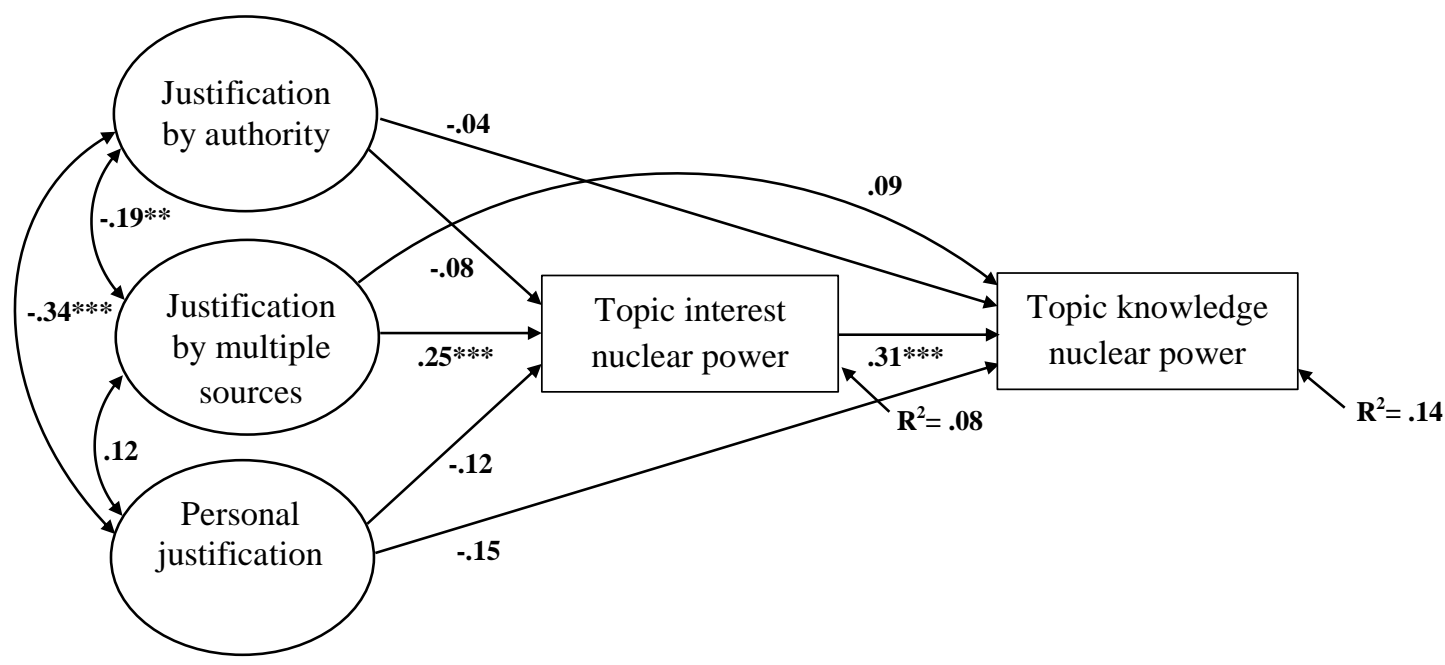

Figure 3

The model for nuclear power with standardized path coefficients and explained variance in the prediction of dependent variables. $* * p<.01, * * * p<.001$. 


\section{Appendix}

Sample Items for the Topic Knowledge Measures

(correct answers are in italics)

\section{Nuclear power}

3. Radioactive waste from nuclear power plants is ...
a) spent radon
b) spent uranium fuel
c) spent bio-fuel
d) spent nuclear power

5. The responsibility for ensuring that nuclear power is used for peaceful purposes is held by..
a) The OECD's Atomic Energy Institute
b) The International Atomic Energy Agency
c) The UN Panel on Climate Change
d) The International Renewable Energy Agency

9. A radioactive element ...
a) has unstable atomic nuclei
b) has stable atomic nuclei
c) is among the lightest elements
d) emits visible radiation

\section{Climate change}

2. The greenhouse effect is due to...
a) holes in the ozone layer
b) increased use of nuclear energy
c) increased occurence of acidic precipitation 
d) streams of heat that do not get out of the atmosphere

e) the pollution of the oceans

5. Some of the most important climate gases are...
a) chlorine and hydrogen
b) oxygen and propane
c) nitrogen oxides and butane
d) propellants and aerosols
e) water vapour and laughing-gas

13. The Kyoto Protocol is...
a) a binding agreement between USA and EU
b) a binding agreement managed by the World Trade Organization (WTO)
c) a binding international agreement managed by the UN
d) ratified by all the large industrialised countries
e) an important agreement about the storing of radioactive waste 